\title{
Transport electrification: the effect of recent battery cost reduction on future emission scenarios
}

\author{
O. Y. Edelenbosch ${ }^{1,2}$ (D) A. F. Hof ${ }^{1,3}$ - B. Nykvist ${ }^{4}$ • \\ B. Girod ${ }^{5}$ • D. P. van Vuuren ${ }^{1,3}$
}

Received: 1 August 2017 / Accepted: 3 July 2018 /Published online: 11 September 2018

(C) Springer Nature B.V. 2018

\begin{abstract}
Although the rapid fall in the costs of batteries has made electric vehicles (EVs) more affordable and boosted their sales, EVs still account for only a fraction of total car sales. In the last years, the battery costs of electric vehicles have dropped faster than previously estimated in the empirical literature. As a result, future cost projections have been adjusted. The larger than expected reduction in costs also shows the uncertainty of battery cost development, which will affect the success of a transition to low-carbon transport. Integrated
\end{abstract}

Electronic supplementary material The online version of this article (https://doi.org/10.1007/s10584-0182250-y) contains supplementary material, which is available to authorized users.

O. Y. Edelenbosch oreane.edelenbosch@pbl.nl
A. F. Hof
Andries.Hof@pbl.nl
B. Nykvist
bjorn.nykvist@sei-international.org
B. Girod
bgirod@ethz.ch
D. P. van Vuuren
Detlef.vanvuuren@pbl.nl

1 PBL Netherlands Environmental Assessment Agency, Bezuidenhoutseweg 30, 2594 AV Den Haag, The Netherlands

2 Department of Management and Economics, Politecnico di Milano, Via Lambruschini 4/B, Milan, Italy

3 Copernicus Institute of Sustainable Development, Utrecht University, Princetonlaan 8a, 3584 CB Utrecht, The Netherlands

4 Stockholm Environment Institute, Linnégatan 87 D, 11523 Stockholm, Sweden

5 Department of Management Technology, and Economics, ETH Zurich, Weinbergstrasse 62, 8032 Zurich, Switzerland 
assessment models show that reducing greenhouse gas emissions is more challenging in the transport sector than in other sectors. Switching to EVs could significantly reduce passenger road-transport emissions. In this study, we test the sensitivity of the projected sales of EVs to different battery costs and climate policy futures. The model suggests that the effectiveness of policy incentives will strongly depend on the battery floor costs, as EVs only gain significant shares (15\% or more) of global car sales within our model framework when battery costs reach $100 \$ / \mathrm{kWh}$ or less. We therefore conclude that besides the pace of the battery costs decline, which has been rapid in the last years, it is important to understand the lower boundary of battery costs for modelling long-term global energy transitions.

\section{Introduction}

If current trends continue, transport sector greenhouse gas emissions are expected to rise faster than those from other energy end-use sectors (IPCC 2014b). Integrated assessment models (IAMs), used to analyse cross-sectoral, system-wide, and end to end strategies for achieving climate targets, show that in the transport sector, fuel switching forms a crucial strategy to reduce the sector's GHG emissions (Edelenbosch et al. 2016; McCollum et al. 2014). These models have been used extensively to inform international climate change mitigation assessments, such as those performed by the Intergovernmental Panel on Climate Change (IPCC) and the Global Energy Assessment (GEA) (GEA 2012; IPCC 2014a). For light duty vehicles (LDVs), which consume around half of the total transport energy (IPCC 2014b), many models show that switching to electricity is an attractive solution (Thiel et al. 2016; Williams et al. 2012). However, the degree and rate at which LDV transport is electrified differs across models (Edelenbosch et al. 2016; Grahn et al. 2016; Thiel et al. 2016). The broad scope of the models does not allow including too many details, resulting in a general representation of the aggregated trends and focussing on financial factors, which are easier to incorporate than non-financial, behavioural factors. Hence, the costs of electric vehicles (EVs), affected by battery cost developments, are an important variable in long-term IAM scenarios.

The costs of EV batteries have fallen rapidly: from some 1000 US\$ per kilowatt-hour in 2008 to 485 US\$ per kilowatt-hour in 2012 (IEA 2013). Nykvist and Nilsson (2015) argue that the literature is lagging behind technological advances, and actual battery costs are even lower. Using information from leading manufacturers of electric cars, they estimated average costs per kilowatt-hour in 2014 of 300 US\$, whereas the average reported in the literature was 410 US\$ per kilowatt-hour. One of the leading battery models, the Argonne BatPac, even shows costs between 190 and 330 US $\$ / \mathrm{kWh}$ in 2015 (Sakti et al. 2015). It is indisputable that battery costs are falling rapidly. The recent developments of battery costs have led to future projections of the reduction rate as well as the floor costs being updated. However, reported values are not always easy to compare, due to market mechanisms and variations in battery structure, chemistry, and technological design (IEA 2015a), and hence, the debate on current battery costs and their projected development is ongoing. This uncertain future could have significant implications for the projected transition to LDV electrification by energy and transport system models (IEA 2015a).

Another key assumption affecting EV prices in IAMs is the assumed battery energy capacity. IAMs typically use average vehicle data, representing the needs of the average consumer. Although technically speaking, the energy requirements of the large majority 
of vehicle-days can be fulfilled by a vehicle with a battery size of only $19.2 \mathrm{kWh}$ (Needell et al. 2016), the currently available EVs vary greatly in battery capacity and attract different types of users. Larger-capacity batteries cost more to buy, but have a longer driving range, so are more appreciated by consumers (Hidrue et al. 2011). Ellingsen et al. (2016) describe four typical types of EVs, ranging from a mini car with a battery of $17.7 \mathrm{kWh}$ and a range of $133 \mathrm{~km}$ to a luxury car with a battery of $60 \mathrm{kWh}$ and a range of $317 \mathrm{~km}$ (Linda Ager-Wick et al. 2016). Most of the vehicles sold in 2016 and 2017 by the leading manufacturer Tesla Motors had an even larger battery of 75 or $90 \mathrm{kWh}$, and battery packs of $100 \mathrm{kWh}$ have now been introduced (EV-volumes 2018). Advances in battery technology that significantly speed up charging could however reduce the need for largecapacity batteries (IEA 2018). The question here is how the assumed battery size for an "average" user, comparable to an "average" conventional vehicle, affects the projected vehicle transition by IAMs.

To understand how recent technological developments might affect the anticipated technology transition in the transport sector, IAMs need to take account of a more diverse set of EV purchase price scenarios than the current "single trajectory assumptions". We assess how the projected speed and magnitude of a transition to battery electric vehicles (BEVs) is influenced by model assumptions on four factors: (1) the battery costs per kilowatt-hout, (2) the impact of carbon pricing, (3) the impact of targeted EV policy incentive schemes, and (4) battery capacity. We used a state-of-the art IAM, i.e., the Integrated Model to Assess the Greenhouse Effect (IMAGE), which contains a relatively detailed transport submodule compared to other IAMs.

In the analysis, we first focus on the short term, incorporating the current EV policy incentive schemes. Next, we focus on the longer term (up to 2050) under varying policy and battery capacity assumptions. The calculations in this paper confirm that EV deployment is indeed highly sensitive to the projected battery costs. However, in the long run, the assumed ultimate cost (the floor cost) is found to be even more important than the rate of cost decline. Given the standard IMAGE model assumptions, a floor cost of $100 \mathrm{US} \$ / \mathrm{kWh}$ could, even in the absence of climate policy, make BEVs competitive with alternatives and thus allow BEVs to make up $15 \%$ of the market in 2045 . A higher battery cost of $150 \mathrm{US} \$ / \mathrm{kWh}$, however, would not achieve cost parity and thus leads to only a negligible share if no policies to stimulate EVs are in place. In the long term, the key question is therefore not only how rapidly costs fall, but also how low they can go.

\section{Scenario analysis}

The IMAGE transport model is described in detail in Girod et al. (2012). A summary of the key transport model equations and assumptions are provided in the Supporting Materials, as well as of the general IMAGE modelling framework.

We defined several scenarios that differ with regard to (1) the battery costs per $\mathrm{kWh},(2)$ carbon pricing, (3) EV subsidy schemes, and (4) battery capacity assumptions (see Table 1). The battery cost scenarios are designed based on the range of current cost estimates and possible implications for future costs. The carbon pricing and EV subsidy schemes include different assumptions on future climate policy and continuation of current policies. Finally, the battery capacity scenarios examine the sensitivity of the results for a broad range of alternative battery capacity assumptions. 
Table 1 Scenario framework

\begin{tabular}{|c|c|c|c|}
\hline Battery costs & Climate policy & EV subsidies & $\begin{array}{l}\text { Battery capacity } \\
\text { (sensitivity) }\end{array}$ \\
\hline $\begin{array}{l}\text { - Reference (REF) } \\
\text { - Market leaders (ML) } \\
\text { - Optimistic market } \\
\text { leaders (OML) } \\
\text { - Optimistic floor costs } \\
\text { (OF) }\end{array}$ & $\begin{array}{l}\text { - No climate policy (default) } \\
\text { - Carbon tax rising to } \\
249 \mathrm{US} \$ / \mathrm{tCO}_{2} \text { in } 2050\end{array}$ & $\begin{array}{l}\text { - Current subsidies } \\
\text { removed after } 2020 \\
\text { (default) } \\
\text { - Current incentives } \\
\text { scaled globally to } 2050\end{array}$ & $\begin{array}{l}\text { - } 45 \mathrm{kWh} \text { (default) } \\
\text { - Sensitivity tested } \\
\text { from } 30 \text { to } 90 \mathrm{kWh}\end{array}$ \\
\hline
\end{tabular}

\subsection{Battery costs}

As mentioned earlier, estimated current BEV battery costs vary widely. In 2015, Nykvist and Nilsson calculated an average cost of $410 \mathrm{US} \$ / \mathrm{kWh}$, which fell to $300 \mathrm{US} \$ / \mathrm{kWh}$ when they averaged only the estimates of market-leading BEV manufacturers. The associated $95 \%$ confidence intervals for their log models were respectively 250-670 and 140-620 US\$/ $\mathrm{kWh}$. In our reference scenario, the battery costs follow Argonne National Laboratory's battery cost projections, which for 2015 are in line with the average projections Nykvist and Nilsson (2015) describe (including literature and manufacture statements). In the other two scenarios, lower battery costs of $300 \mathrm{US} \$ / \mathrm{kWh}$ are assumed in 2015 (see Fig. 1). As our focus is on the effects of different BEV costs on vehicle transition pathways, we use exogenous cost projections here. However, in the Supporting Materials, for comparison, we also provide results for endogenous cost pathways, i.e. costs based on previous BEV sales.

Nykvist and Nilsson published their research in 2015; in late 2016, General Motors released the Chevrolet Bolt EV, priced at 37500 US\$, and disclosed that battery cells cost 145 US\$/ $\mathrm{kWh}$, which would fall further to $100 \mathrm{US} \$ / \mathrm{kWh}$ by 2022 (EVObsession 2015). The pack integration costs are estimated to increase costs by about $50 \%$, which implies that the pack cost is currently $218 \mathrm{US} \$ / \mathrm{kWh}$ and could be $150 \mathrm{US} \$ / \mathrm{kWh}$ by 2022 (Voelcker 2016). Tesla Motors has revealed pack costs of less than $190 \mathrm{US} \$ / \mathrm{kWh}$ (Voelcker 2016). Given these figures, in the second scenario, the "market leaders" scenario (ML), battery cost falls to 150 US $\$ / \mathrm{kWh}$ by

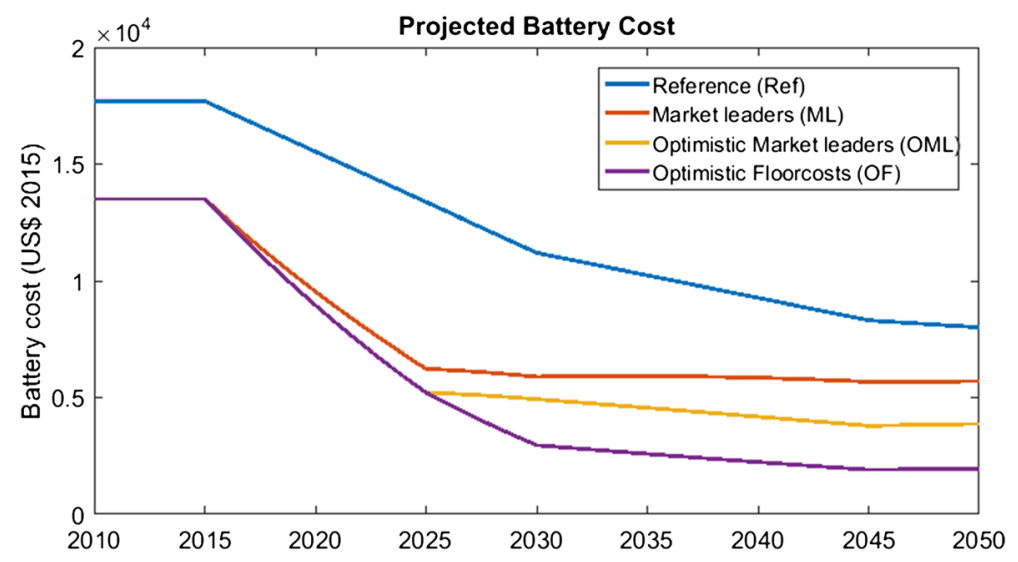

Fig. 1 Projected battery costs in the reference (Ref), market leaders (ML), optimistic market leaders (OML), and optimistic floor costs (OF) scenarios. The costs per kWh for each scenario are indicated in Table 2. For these four scenarios, the battery capacity of the BEV is $45 \mathrm{kWh}$ in 2015 and decreases to $38 \mathrm{kWh}$ by mid-century 
2025. In the third scenario, the "optimistic market leaders" scenario (OML), it is assumed that battery costs would fall to 125 US $\$ / \mathrm{kWh}$ by 2025 (the US Department of Energy battery pack cost target for 2022 (Faguy 2015)), and to 100 US $\$ / \mathrm{kWh}$ by 2045. Lowering costs to 100 US $\$ /$ $\mathrm{kWh}$ by the second half of the century is consistent with the more optimistic assumptions in Sakti et al. (2015) and the recently published EV outlook (IEA 2018). In the last year (during the process of publication of this article), Kittner et al. (2017) has forecasted prices from suppliers of battery packs to be $124 \mathrm{US} \$ / \mathrm{kWh}$ in 2020 and Berckmans et al. (2017) projected even lower battery cost projections of 50-75 $\$ / \mathrm{kWh}$ in 2030 , due to improvements in materials used as well as mass-manufacturing. Therefore we have added a fourth scenario, "Optimistic Floor costs" (OF), which follows the OML battery costs projections until 2025 and then dropping to $75 \$ / \mathrm{kWh}$ in 2030 and $50 \$ / \mathrm{kWh}$ in 2045. In the ML, OML, and OF scenarios, the battery costs follow different pathways but the other elements that impact the vehicle cost are assumed to remain at their original cost price projection. For all four scenarios, the additional vehicle purchase costs, compared to a conventional ICE, are shown in Table 2 and the total battery costs are shown in Fig. 1. For more details on the LDV costs assumptions, see the Supporting Materials.

\subsection{Climate policy}

In IMAGE, climate policy is usually modelled by introducing a carbon price (i.e. a price assigned to $\mathrm{CO}_{2}$ emissions) into the model, which represents a generic measure to simulate policy measures that reduce emissions cost efficiently throughout all the different sectors. In the transport sector, the carbon price reduces the competitiveness of transport technologies and transport modes that rely on fossil fuels, and also the demand for transportation.

To reflect the possible influence of climate policy, we ran the default case without climate policy and included a climate policy scenario in which a globally uniform carbon price was applied, following the standard IMAGE SSP2-2.6 price trajectory (van Vuuren et al. 2017). In the IMAGE model baseline, this leads to a radiative forcing of $2.6 \mathrm{~W} / \mathrm{m}^{2}$ in 2100 (i.e., starting at $47 \mathrm{US} \$ / \mathrm{tCO}_{2}$ in 2020 and increasing to $249 \mathrm{US} \$ / \mathrm{tCO}_{2}$ in 2050).

Consumers can save money in the long term by buying efficient EVs instead of conventional internal combustion engines (ICEs) when fuel prices increase as a result of the implementation

Table 2 Vehicle cost details of the three battery cost scenarios in 2015 US\$, based on the Argonne National Laboratory "Literature review" scenario. The battery capacity of the BEV with a range of $240 \mathrm{~km}$ is $45 \mathrm{kWh}$ in 2015, which by mid-century has decreased to $38 \mathrm{kWh}$

\begin{tabular}{|c|c|c|c|c|c|}
\hline & & 2015 & 2025 & 2030 & 2045 \\
\hline \multirow[t]{3}{*}{ 1. Reference (Ref) } & Battery cost (US\$/kWh) & 394 & 321 & 284 & 219 \\
\hline & Cost of battery & 17,704 & 13,369 & 11,202 & 8301 \\
\hline & Additional cost vis-à-vis ICE & 25,462 & 19,140 & 15,980 & 11,487 \\
\hline \multirow[t]{3}{*}{ 2. Market leaders (ML) } & Battery cost (US\$/kWh) & 300 & 150 & 150 & 150 \\
\hline & Cost of battery & 13,484 & 6185 & 5907 & 5690 \\
\hline & Additional cost vis-à-vis ICE & 19,132 & 8364 & 8037 & 7571 \\
\hline \multirow{3}{*}{$\begin{array}{l}\text { 3. Optimistic market } \\
\text { leaders (OML) }\end{array}$} & Battery cost (US\$/kWh) & 300 & 125 & 125 & 100 \\
\hline & Cost of battery & 13,484 & 5154 & 4922 & 3794 \\
\hline & Additional cost vis-à-vis ICE & 19,132 & 6818 & 6560 & 4725 \\
\hline \multirow[t]{3}{*}{ 4. Optimistic floor costs (OF) } & Battery cost (US\$/kWh) & 300 & 125 & 75 & 50 \\
\hline & Cost of battery & 13,484 & 5154 & 2953 & 1897 \\
\hline & Additional cost vis-à-vis ICE & 19,132 & 6818 & 3607 & 1880 \\
\hline
\end{tabular}


of a carbon tax. However, vehicle choice is not purely rational and consumers expect very short payback periods (2-3 years (Tran et al. 2012)) which makes it unlikely that efficiency will be an important factor in an LDV technology transition. This is reflected in IMAGE by discount rates for vehicle purchase. In accordance with Train's literature review (Train 1985), the applied discount rates decrease with income, falling from $20 \%$ for an average per capita income of 10,000 US\$ to $5 \%$ for a per capita income of 55,000 US\$ (Girod et al. 2012).

\subsection{EV subsidies}

Subsidies can be more effective than a carbon tax in stimulating EV deployment, as they directly reduce the cost difference of the EVs compared to ICEs (Jin et al. 2014). Our default scenario assumes that current EV subsidies are removed after 2020. To examine possible effects of long-term EV subsidies, we also formulated a scenario, where the average current EV subsidy levels (which vary, depending on whether vehicles are battery-operated or plug-in) are implemented globally from 2020 onwards, after which they are kept constant relative to vehicle costs.

\subsection{Sensitivity to battery capacity}

Novel vehicle technologies are typically introduced first in expensive vehicles (for which consumers are prepared to pay more because of the extra functionality) and later in mid- and low-price vehicles, but hybrid electric technology was first introduced in compact cars, as this segment is more sensitive to fuel savings (Weiss et al. 2012), and the lighter the vehicle, the less energy capacity the battery requires (Linda Ager-Wick et al. 2016). Later, hybrid electric technology was applied to larger vehicles too. Currently, the EV sales data shows a diverse portfolio of battery capacity introduced in different vehicle price categories, with marked regional differences in preference for battery capacity (EV-volumes 2018). Larger-capacity battery packs in high-price vehicles, enabling longer ranges at high costs, are currently gaining market share in the USA, for example, while short-range "city cars" account for an important share of the market in Japan and China. In the USA in 2017, the battery capacity of the top 3 BEVs sold ranged from 60 to $90 \mathrm{kWh}$ (which is at least $67 \%$ of the BEV market). In China, the average battery capacity of the top seven of the BEVs sold (at least $44 \%$ of the BEV market) in that year was $30 \mathrm{kWh}$ (EV-volumes 2018).

Clearly, the diversity of battery capacities available is a key element in the transition to EVs attracting different types of users and determining both costs and the car's range. In global models, focussing on aggregated trends, often one BEV battery capacity is assumed, as consumers are represented as a single user. In this simplified representation, an assumption needs to be made on the average battery capacity that is valued equally to an average conventional ICE. This value is surrounded by uncertainty and could differ over time related to the development of consumer preferences, charging speeds, storage, and load schemes. Here, we are interested in the sensitivity of the projected results to model assumptions about average battery capacity. The scenarios investigated assume battery capacities ranging between 30 and $90 \mathrm{kWh}$ (constant over time), in steps of $10 \mathrm{kWh}$, for all four costs scenarios. Note that although we considered different battery capacities, the other vehicle costs we used in our modelling are based on average cars assumptions; more detailed modelling is needed to understand trends in different car market segments. In addition, we only consider the financial aspects of the battery capacity and not the non-financial benefits of larger capacity. 


\section{$3 \mathrm{EV}$ sales in the short term}

Figure 2 shows the short-term effect of battery cost projections on vehicle sales for three countries with subsidies (Japan, USA, and China) and one without (Brazil) in 2020 (IEA 2015b). While the technology costs of the vehicles are assumed to be the same across countries, average energy use, fuel prices, and subsidies are different affecting vehicle deployment. Within the 26 IMAGE regions, the vehicle choice made will depend on the regional developments of for example, fuel price or subsidies. These assumptions, including the height of the subsidies for the different vehicle types and regions, can be found in the Supplementary Materials. Even though the electric vehicle market is recently starting to grow, in 2015, the share in sales in the regions considered here was $1 \%$ or less. The small market share of EVs in 2015 falls within the models' uncertainty range: it was $0.7 \%$ in the USA, $1.0 \%$ in China, $0.6 \%$ in Japan (IEA 2016), and too small to be used to validate our model results against.

The figure shows that the range of future battery cost estimates already has an effect in the short term on the projected EV penetration. The projected EV sales significantly increase by 2020 for values at the low end of the range in those regions with EV subsidies in place. With the exception of Norway where $39.4 \%$ of sold cars were EVs, in 2017 EV sales in many countries were in the order of 1-2\% (e.g. USA 1.2\%, China 2.2\%, Japan 1.0\%, Brazil 0.4\%). Reaching shares over $20 \%$ in these regions by 2020 (as seen in the low cost scenarios) does not seem plausible and could be explained by several factors that are not modelled which could
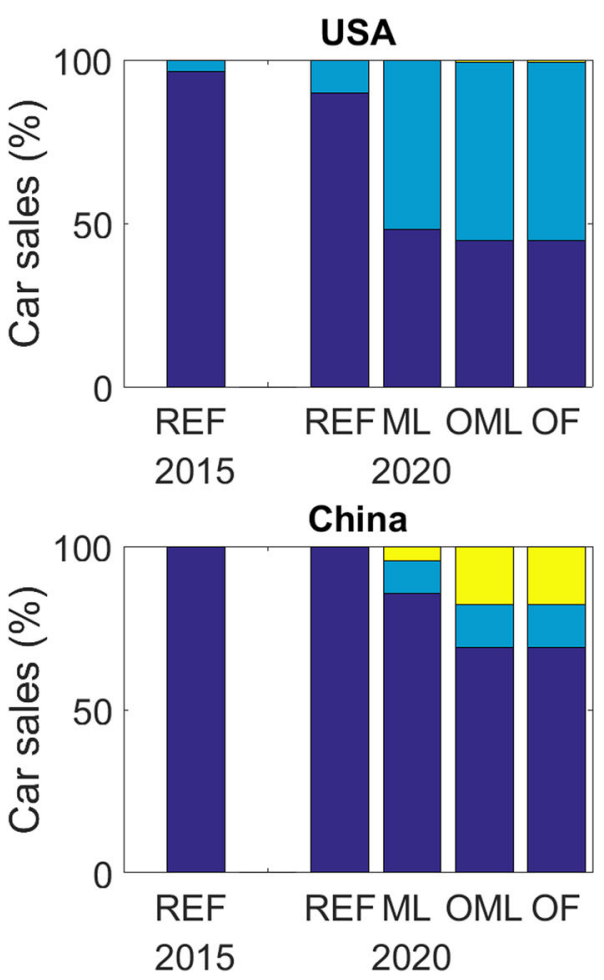

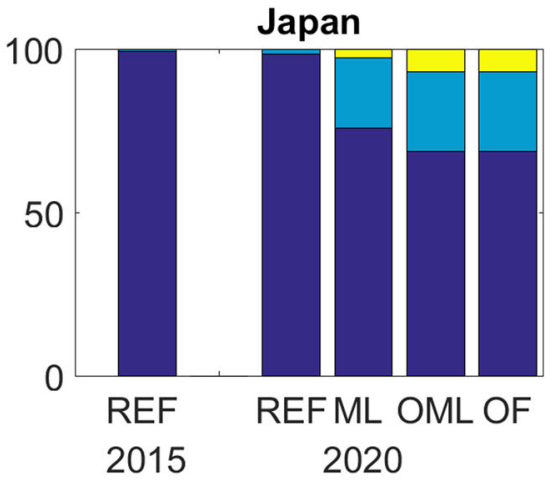

Brazil

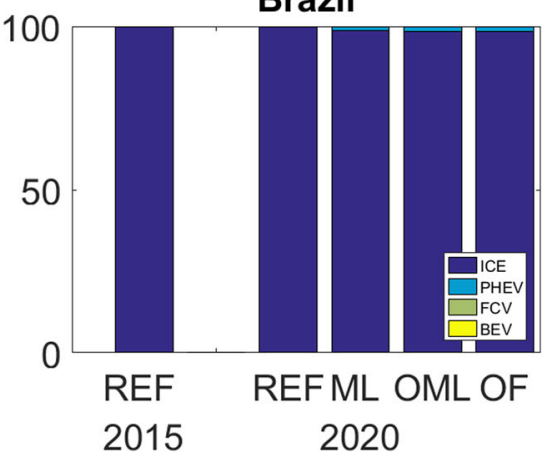

Fig. 2 Reference car sales in 2015 alongside projected car sales in the USA, Japan, China, and Brazil in 2020 REF, ML, OML, and OF battery cost assumptions. The OF and OML scenarios follow the same cost pathway until 2020 therefore show identical results 
delay the transition towards EV sales (e.g. the time needed to develop markets and infrastructure). Indeed, IAMs are not designed for short-term projections, and as such, the projected short-term regional results should not be regarded as model or scenario validation. Instead, they provide insight into the model sensitivity to battery cost assumptions across regions.

In China for example, there is no BEV deployment under the reference assumptions in 2020, but deployment would be 5\% under the ML assumptions and $18 \%$ under the OML assumptions. The combination of the higher subsidy for BEVs in China and the technology development leading to less costly batteries eventually results in BEVs that are cost competitors with ICEs in this scenario. China's policy ambition is to have five million EVs on the road by 2020 , which is roughly comparable to the ML cost scenario projections. However, specific urban policies are planned to put in place to enable this transition, which are not reflected within the model. In the USA, the BEV subsidy is lower than that in China while smaller plugin in electric vehicles (PHEVs) receive a substantial subsidy. This combined with the higher energy use per km (due to different driving styles, average vehicle size, and load factor) and the relatively high electricity price and low oil price leads to the difference in projected vehicle shares in the USA compared to China. Japan shows results that are more similar to China. Here, the lower EV share can be explained by the lower EV subsidy.

The incentive schemes affect strongly the EV sales in the ML and OML scenarios. In our example of Brazil, where no subsidies are in place, none of the costs scenarios show a transition to EVs. This also holds for other regions without subsidies. In the reference costs scenario, with the subsidies in place, PHEVs attain small market shares in Japan and the USA, but BEVs do not enter the market, as their costs remain too high. The effect of financial incentives on BEV deployment has also been empirically observed (Mock and Yang 2014).
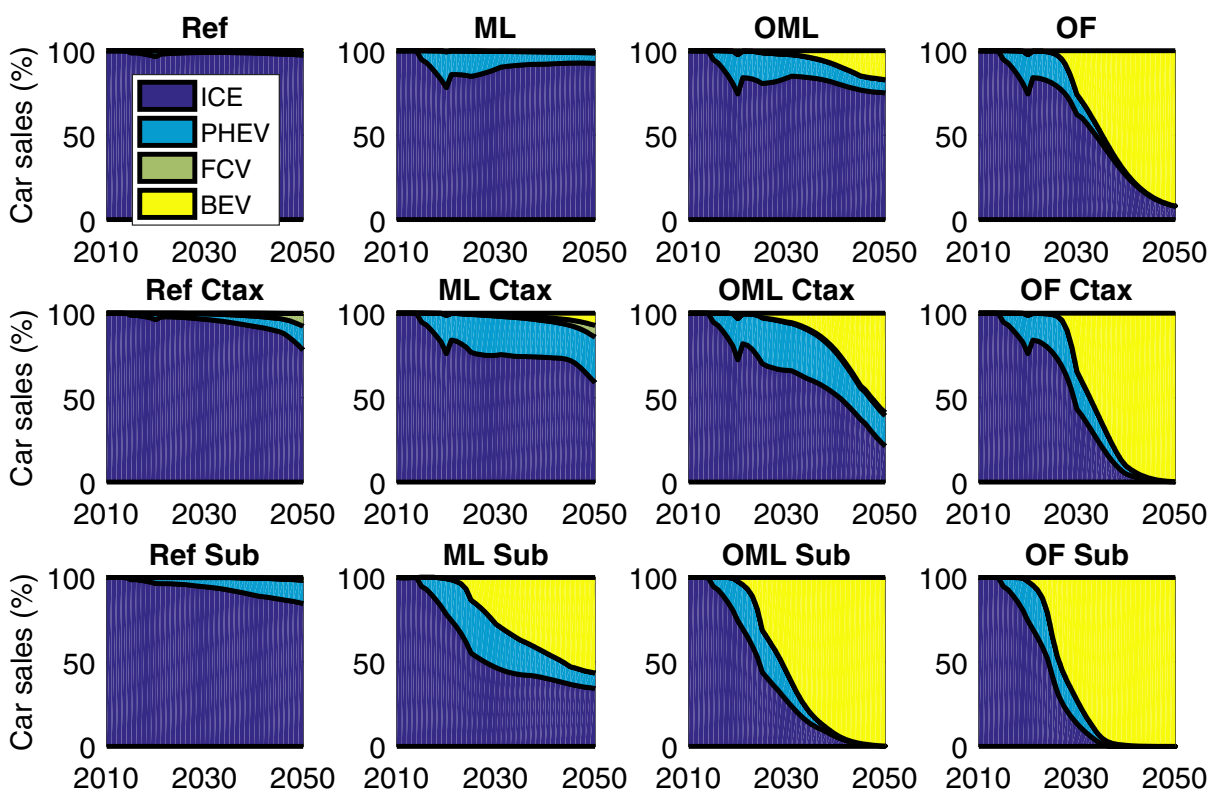

Fig. 3 Global vehicle sales for the three battery cost scenarios (REF ML, OML, and OF). In the top row, no additional policy measures are assumed after 2020; in the second row, the reference carbon price to meet a 2degree scenario is in place; in the bottom row, average current national direct subsidies are introduced globally into all IMAGE regions between 2020 and 2050 


\section{$4 \mathrm{EV}$ sales in the long term}

\subsection{Deployment in the absence of climate policy and EV subsidies}

The trend in battery costs also has important implications for EV take-up, both for PHEV and BEVs, in the longer term (Fig. 3 first row; note that current subsidies have been removed after 2020). While in the reference and ML scenarios BEVs remain too expensive to attain a significant share in the global market, the decrease of battery costs in the OML scenario to $100 \mathrm{US} \$ / \mathrm{kWh}$ leads to BEV achieving a $15 \%$ share in 2045 without any additional policy. The additional vehicle price in the latter case is approximately 4700 US\$ according to our assumptions, while in the ML scenario it is approximately 7500 US\$, (see Supporting Materials). According to Tran et al. (2012), only $6 \%$ of consumers would be willing to pay more than 3000 US\$ extra for a BEV, which is more pessimistic than the results from our modelling. However, both studies show that only when the additional price of BEVs has fallen to a few thousand dollars do BEVs become an attractive option. So, besides the pace of the battery costs decline that has been observed in the last years, it is also important to understand the lower boundary (the floor price) of battery costs. While the battery cost reduction leads to higher PHEV shares (difference between ML and OML), across the scenarios and over time there appears to be "maximum" penetration, where lowering the battery cost further leads to substitution of PHEVs by BEVs. The importance of the floor price is further demonstrated by the OF scenario. If after 2025 the battery cost would continue to drop to $75 \$ / \mathrm{kWh}$ and eventually $50 \$ / \mathrm{kWh}$ in 2045 , a close to full transition would take place without additional policy measures, according to the model projections. It is noteworthy that while we consider this scenario optimistic, it is in line with some of the most recent literature on battery cost development in the coming decade.

\subsection{Impact of climate policy}

Since the payback period of consumers is very short, the effect of a carbon price is small if the price penalty (extra investment cost) of EVs is too large. The second row of Fig. 2 shows that this is the case in the REF scenario. In the original baseline, the "normal" representation of climate policy is therefore not effective. However, if the costs difference between BEVs and conventional technologies is in the range of the OML scenario, a carbon price can have a large impact. The projected costs of transport technologies thus strongly influence the effectiveness of a carbon price to induce a transition to EVs. In the ML scenario, which follows progressive EV market leader statements but in which battery costs do not decrease below $150 \mathrm{US} \$ \mathrm{kWh}$, BEV deployment remains below $10 \%$, even under the assumption of stringent climate policy, showing that again the key obstacle to transition is the floor price. While this analysis does not include fuel cell vehicle (FCV) specific policies, the combined effect of ML cost and a carbon tax results in attaining a small share in car sales in 2050.

\subsection{Impact of EV subsidies}

The model results confirm that EV sales respond to direct EV capital cost subsidies: see the effect of the subsidy removal in 2020 (top two rows of Fig. 3) and the high EV sales under the assumption of continuation of current subsidies (but implemented 


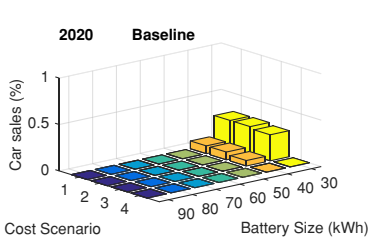

2035

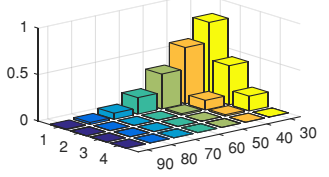

2050

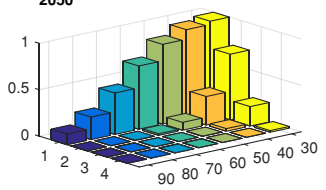

$2020 \quad 450$ ppm Carbon tax
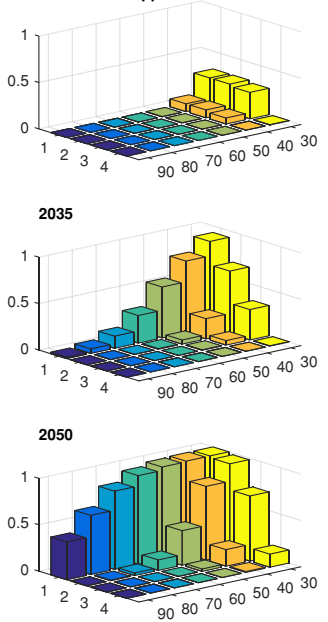

2020 Subsidy to 2050

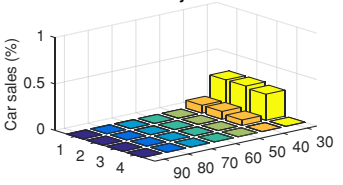

2035
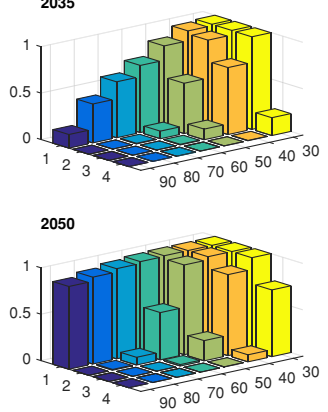

Fig. 4 Global BEV share in the vehicle fleet for three scenarios under varying assumptions of average battery capacity. The cost scenario are numbered as follows; 1:REF, 2:ML, 3:OML and 4: OF.

globally) up to 2050 (third row). Subsidies are often present to stimulate initial sales and many countries have stated that EV subsidies will be removed after a certain number of vehicles have been sold (Mock and Yang 2014). This scenario, in which subsidies are not only maintained but are also applied globally, does not aim to be realistic, but shows that the models' representation of climate policy (through a carbon price or alternative measures) can have a large effect on the sector's projected mitigation potential. Lower discounting of consumer savings over the lifespan of vehicles will have a similar impact.

\subsection{BEV range and battery capacity}

The direct sensitivity of the BEVs' assumed average battery capacity on BEV car sales can be seen in Fig. 4. As expected, if it is assumed that larger battery capacities are required, with correspondingly higher costs, deployment will be lower-as only the financial aspects of the larger battery capacity are considered. The large range of BEV shares across scenarios demonstrates the importance of understanding what battery capacity size is assumed in the models to be compatible to an average conventional car. In the optimistic cost scenario (OML), a BEV with a battery capacity of $60 \mathrm{kWh}$, which corresponds to a range of approximately $350 \mathrm{~km}$, would attain $2 \%$ of global market sales in 2050 in the baseline scenario and $11 \%$ under the carbon tax scenario. However, a smaller capacity battery of $30 \mathrm{kWh}$, corresponding to a range of approximately $180 \mathrm{~km}$, could account for the majority of the sales in the OML (but not in the ML) scenario in 2050, even without additional climate policy or EV subsidies. At the other end of the battery capacity spectrum, the model shows that vehicles with battery capacities of 90 or $80 \mathrm{kWh}$ will not become competitive against ICEs even with the attractive subsidies in place and optimistic (OML) technology cost assumptions. Along that same line, the optimistic floor price (OF) scenario shows sales dropping to 24 and $12 \%$ under 80 and $90 \mathrm{kWh}$ assumptions respectively. 


\section{Discussion and conclusions}

Transitioning from conventional ICEs to EVs could be a way to mitigate transport GHG emissions (assuming electricity is generated with low GHG emissions). IAMs are useful tools to analyse cross-sectoral relations while assessing mitigation pathways, in which the electrification of the transport sector can play an important role. A successful electric vehicle transition affects penetration rates of competing technologies such as cars on biofuels and hydrogen, and possibly the emission reduction potential of the transport sector. Other sectors represented within the IAM context, such as the electricity sector and the land use sector, can also be affected by the projected changes. EVs are currently more expensive than conventional vehicles, mainly because of the costs of the battery. This study shows that if the recent rapid fall in battery costs continues, this could accelerate the projected transition to EVs in the future. For long-term projections such as performed by IAMs, however, understanding the battery floor cost is even more important.

There are important scenario assumptions that influence these findings. The assumed average battery capacity needed to compete with a conventional ICE is a key uncertainty. Current (2017) sales show a large variation in average battery capacity, and the outlook is highly uncertain. The added benefits of increased vehicle range are currently resulting in the deployment of larger-capacity battery EVs. However, this might change if charging speeds would increase. It could be assumed that all regions will follow the US trend and Tesla's product line and transition to BEVs with larger-capacity batteries. Alternatively, and consistent with ongoing urbanization, the demand could increase for the smaller BEVs that have gained a foothold in China and Japan. Finally, recent analysis by IEA using the ANL BatPac model (IEA 2018) indicates a rather strong effect of lower battery pack cost as a function of pack size which has not been taken into account in our analysis. If such a relationship holds also in the future, this favours larger battery packs. From our battery capacity sensitivity analysis, it can be concluded that the projected BEV share is very sensitive to these future developments.

Consumer perception towards EV plays a major role in adoption of EVs (Rezvani et al. 2015). The consumer's attraction to a car, quantified by discrete choice studies as willingness to pay for longer-range vehicles, is not taken into account in our model, nor is the effect of the battery capacity assumption on car weight, technology learning, or vehicle use (e.g., urban or rural environment). Hidrue et al. (2011) show that the median willingness to pay for a BEV with a range of 300 miles, 1-h charging time, and 20\% faster acceleration is 9625 US\$, while for a 100-mile BEV with less attractive characteristics it would be $-5606 \mathrm{US} \$$. Compared to a conventional car, certain BEV configurations can thus be seen as advantageous and others as disadvantageous. Clearly, taking the above preferences into account would change our scenario results significantly. Similarly, factors such as the level of access to charging infrastructure (Lin 2014) and two car households, which reduce desired range (Jakobsson et al. 2016), as well as charging time (Egbue and Long 2012), which are important barriers to diffusion of electric vehicles (Biresselioglu et al. 2018), are not taken in to account. Finally, the development of additional aspects of total cost of ownership such as maintenance, depreciation, and repairs is still uncertain for BEVs compared to conventional vehicles (Breetz and Salon 2018). Still, our scenarios show that in a simplified model that assumes one consumer market, and in which decisions are based on costs, average battery capacity is a key assumption.

Willingness to pay varies per person (Hidrue et al. 2011). In global models, such as IMAGE, it can be too constraining to consider different consumer preferences, as these differ 
over time and place; limited data is available and this would make the model considerably more complex. Therefore, generally simple relationships are used in the model based on aggregated trends and assuming average technology characteristics and consumer behaviour. In IMAGE, for example market heterogeneity is represented by the more stylized multinomial logit equation. However, in a technology transition, heterogeneous consumer preferences can also play an important role. Morton et al. (2017), for example, identify specific clusters in the UK which are unlikely to enter the EV market in the short term. The relationships between market deployment and willingness to pay can be dynamic (for example, through social influence), and so can those between market deployment and technology cost (through learning effects). Early adopters and thus also heterogeneity in preferences can trigger a transition; ideally, these dynamics should be accounted for, even in models with global scope.

The discount rate is important in the decision to buy a car. A large advantage of the EV is that the energy costs per $\mathrm{km}$ are much lower, but future savings are less valued than up-front capital costs by consumers with high discount rates. The literature suggests that consumers expect a short payback time on vehicle purchase, which affects the effectiveness of the current representation of climate policy (a global carbon price) in the model. Under these discount rate assumptions, as long as the extra cost of EVs is higher than that of conventional cars, the carbon price will have a limited effect. Continuing current EV subsidies and applying them globally would be more effective to mitigate transport emissions. Other sector-specific policy measures, such as emissions standards (the current EU target is to achieve a fleet average for all new cars of $95 \mathrm{~g}$ of $\mathrm{CO}_{2}$ per vehicle $\mathrm{km}$ ), could also be more effective and could push car manufacturers to invest in and subsequently subsidize low-emission vehicles.

While this study focuses on battery electric vehicle costs, fast-declining costs have occurred for other technologies (such as solar panels) as well. Ideally, a modeller would like to base their projected technology development on estimates reported by the literature to ensure transparency on the methods and sources. However, in a fast developing market, the time lag between new observations, peer reviewed publication, and model implementation could systematically lead to falling behind. Even within the timespan of writing and publishing this paper the battery cost projections have been further reduced, and prompted the adoption of a newly developed OF scenario to illustrate this progress.

In conclusion, the fall of battery costs for EV applications has sparked the initial sales of PHEVs and EVs, with three million electric cars on the road worldwide in 2017, bringing a transition to EVs closer to reality. If battery costs continue to drop, as several electric car manufacturers have suggested can occur already in the near term, this trend is projected to continue. However, in the long-term, the model projections show that the feasibility of a full transition to meet stringent climate targets depends strongly on the lower limit of battery cost and battery capacity development.

Funding information The research leading to these results received funding from the European Union's Seventh Framework Programme FP7/2007-2013, under grant agreements 308329 (ADVANCE) and 603942 (PATHWAYS).

\section{References}

Berckmans G, Messagie M, Smekens J, Omar N, Vanhaverbeke L, Van Mierlo J (2017) Cost projection of state of the art lithium-ion batteries for electric vehicles up to 2030. Energies 10:1314

Biresselioglu ME, Kaplan MD, Yilmaz BK (2018) Electric mobility in Europe: a comprehensive review of motivators and barriers in decision making processes. Transp Res A 109:1-13 
Breetz HL, Salon D (2018) Do electric vehicles need subsidies? Ownership costs for conventional, hybrid, and electric vehicles in 14 US cities. Energy Policy 120:238-249

Edelenbosch O.Y. et al (2016) Decomposing passenger transport futures: comparing results of global integrated assessment models. Transp Res D 55:281-293

Egbue O, Long S (2012) Barriers to widespread adoption of electric vehicles: an analysis of consumer attitudes and perceptions. Energy Policy 48:717-729

Ellingsen LAW, Singh B, Strømman AH (2016) The size and range effect: lifecycle greenhouse gas emissions of electric vehicles. Environ Res Lett 11(5):054010

EVObsession (2015) \$145 kWh battery cell costs at Chevy Bolt launch, GM says. Accessed 28-1-2017

EV-volumes (2018) The electric vehicle world sales database. Accessed 20-feb-2017 2018

Faguy (2015) Overview of the DOE Advanced Battery R\&D Program. Accessed 28-1-2017 2017

GEA (2012) Global energy assessment — toward a sustainable future. Chapter 9-energy end-use: transport. In Global energy assessment-toward a sustainable future pp. 575-648. Cambridge University Press, Cambridge, UK and New York, NY, USA and the International Institute for Applied Systems Analysis, Laxenburg, Austria

Girod B, van Vuuren DP, Deetman S (2012) Global travel within the 2 C climate target. Energy Policy 45:152166

Grahn M, Brynolf S, Hansson J, Taljegård M (2016) The cost-effectiveness of electrofuels in comparison to other alternative fuels for transport in a low carbon future. In: Conference proceedings. EUBCE, Amsterdam

Hidrue MK, Parsons GR, Kempton W, Gardner MP (2011) Willingness to pay for electric vehicles and their attributes. Resour Energy Econ 33:686-705. https://doi.org/10.1016/j.reseneeco.2011.02.002

IEA (2013) Global EV outlook: understanding the electric vehicle landscape to 2020. International Energy Agency, Paris

IEA (2015a) EV batteries: how quickly are costs falling? International energy agency. Accessed 10-08-2016 2016

IEA (2015b) EV outlook update 1 page. International Energy Agency, Paris

IEA (2016) Global EV outlook 2016: beyond one million electric cars. International Energy Agency, Paris

IEA (2018) Global EV outlook 2018: towards cross-modal electrification. International Energy Agency, Paris

IPCC (2014a) Assessing transformation pathways. In: Climate change 2014: mitigation of climate change. Contribution of Working Group III to the Fifth Assessment Report of the Intergovernmental Panel on Climate Change Cambridge University Press, Cambridge, United Kingdom and New York, NY, USA

IPCC (2014b) Transport. In: Climate change 2014: mitigation of climate change. Contribution of Working Group III to the Fifth Assessment Report of the Intergovernmental Panel on Climate Change Cambridge, United Kingdom and New York, NY, USA

Jakobsson N, Gnann T, Plötz P, Sprei F, Karlsson S (2016) Are multi-car households better suited for battery electric vehicles?-Driving patterns and economics in Sweden and Germany. Transp Res C 65:1-15

Jin L, Searle S, Lutsey N (2014) Evaluation of state-level US electric vehicle incentives The International Council on Clean Transportation

Kittner N, Lill F, Kammen DM (2017) Energy storage deployment and innovation for the clean energy transition. Nat Energy 2:17125

Lin Z (2014) Optimizing and diversifying electric vehicle driving range for US drivers. Transp Sci 48:635-650

Linda Ager-Wick E, Bhawna S, Anders Hammer S (2016) The size and range effect: lifecycle greenhouse gas emissions of electric vehicles. Environ Res Lett 11:054010

McCollum D, Krey V, Kolp P, Nagai Y, Riahi K (2014) Transport electrification: a key element for energy system transformation and climate stabilization. Clim Chang 123:651-664

Mock P, Yang Z (2014) Driving electrification: a global comparison of fiscal incentive policy for electric vehicles The International Council on Clean Transportation (ICCT), Washington DC

Morton C, Anable J, Nelson JD (2017) Consumer structure in the emerging market for electric vehicles: identifying market segments using cluster analysis. International Journal of Sustainable Transportation 11: 443-459

Needell ZA, McNerney J, Chang MT, Trancik JE (2016) Potential for widespread electrification of personal vehicle travel in the United States. Nat Energy 1:16112

Nykvist B, Nilsson M (2015) Rapidly falling costs of battery packs for electric vehicles. Nat Clim Chang 5:329_ 332. https://doi.org/10.1038/nclimate2564 http:/www.nature.com/nclimate/journal/v5/n4/abs/nclimate2564. html\#supplementary-information

Rezvani Z, Jansson J, Bodin J (2015) Advances in consumer electric vehicle adoption research: a review and research agenda. Transp Res Part D: Transp Environ 34:122-136

Sakti A, Michalek JJ, Fuchs ER, Whitacre JF (2015) A techno-economic analysis and optimization of Li-ion batteries for light-duty passenger vehicle electrification. J Power Sources 273:966-980

Thiel C, Nijs W, Simoes S, Schmidt J, van Zyl A, Schmid E (2016) The impact of the EU car CO 2 regulation on the energy system and the role of electr-mobility to achieve transport decarbonisation. Energy Policy 96: $153-166$ 
Train K (1985) Discount rates in consumers' energy-related decisions: a review of the literature. Energy 10: 1243-1253

Tran M, Banister D, Bishop JD, McCulloch MD (2012) Realizing the electric-vehicle revolution. Nat Clim Chang 2:328-333

van Vuuren DP et al (2017) Energy, land-use and greenhouse gas emissions trajectories under a green growth paradigm. Glob Environ Chang 42:237-250

Voelcker J (2016) Electric-car battery costs: Tesla \$190 per kwh for pack, GM \$145 for cells. Green Car Reports. Accessed 28-1-2017 2017

Weiss M, Patel MK, Junginger M, Perujo A, Bonnel P, van Grootveld G (2012) On the electrification of road transport-learning rates and price forecasts for hybrid-electric and battery-electric vehicles. Energy Policy 48:374-393. https://doi.org/10.1016/j.enpol.2012.05.038

Williams JH et al (2012) The technology path to deep greenhouse gas emissions cuts by 2050: the pivotal role of electricity. science 335:53-59 